\title{
Poststroke Pain
}

\author{
Seoyon Yang, $\mathrm{MD}^{1} \quad$ Min Cheol Chang, $\mathrm{MD}^{2}$ \\ 1 Department of Rehabilitation Medicine, Ewha Woman's University \\ Seoul Hospital, Ewha Woman's University School of Medicine, \\ Seoul, Korea \\ 2 Department of Rehabilitation Medicine, College of Medicine, \\ Yeungnam University, Daegu, Republic of Korea
}

Address for correspondence Min Cheol Chang, MD, Department of Physical Medicine and Rehabilitation, College of Medicine, Yeungnam University, 317-1 Daemyungdong, Namku, Taegu 705-717, Republic of Korea (e-mail: wheel633@gmail.com).

Semin Neurol 2021;41:67-74.

\author{
Abstract \\ Keywords \\ - poststroke pain \\ - central poststroke \\ pain \\ - complex regional pain \\ syndrome \\ - shoulder pain \\ - spasticity-related \\ pain \\ - headache
}

Pain is common but often underrecognized after stroke. Poststroke pain (PSP) hinders recovery, impairs quality of life, and is associated with the psychological state of patients with stroke. The most common subtypes of PSP include central PSP, complex regional pain syndrome, shoulder pain, spasticity-related pain, and headache. The pathophysiologies of these PSP subtypes are not yet clearly understood, and PSP is refractory to conventional treatment in many patients. However, recent studies have proposed potential pathophysiologies of PSP subtypes, which may help prioritize therapies that target specific mechanisms.

Pain after stroke is common, reported in 10 to $45.8 \%$ of cases. ${ }^{1,2}$ It can decrease quality of life and hinder recovery in stroke patients. ${ }^{1,3-6}$ However, owing to impairments in cognition or communication following stroke, PSP is frequently overlooked. If physicians do not actively inquire about the presence of pain, it is frequently undisclosed by patients. PSP is not always responsive to conventional treatments; therefore, treatment of PSP may be challenging in clinical practice. Prognosis of PSP is improved when pain is treated early and aggressively, ${ }^{7}$ highlighting the importance of early recognition.

The most common subtypes of PSP are central poststroke pain (CPSP), complex regional pain syndrome (CRPS), shoulder pain, spasticity-related pain, and headache ( - Table 1). ${ }^{7,8}$ Many patients concurrently experience more than one PSP subtype. The pathophysiologies of these subtypes are not yet clearly elucidated. However, recent studies have proposed potential mechanisms for these subtypes, and based on these, various treatment methods are being actively applied to patients with PSP. Here, we review the common subtypes of PSP, with a focus on their pathophysiology and treatment.

published online January 14, 2021
Issue Theme Acute Stroke; Guest Editors: Navdeep Sangha, MD, and Koto Ishida, MD

\section{Central Poststroke Pain}

CPSP is defined as central neuropathic pain that occurs after stroke. ${ }^{9}$ The nature of this pain can range from aching, dull, and throbbing to sharp, stabbing, shooting, and burning. ${ }^{10}$ The prevalence of CPSP in patients with stroke is between 1 and $12 \%,{ }^{10-12}$ and most commonly develops within 1 to 6 months after stroke. ${ }^{11,13-15}$ CPSP can manifest either spontaneously or by induction. Induced pain results from an increased sensitivity to stimulation (hyperesthesia), which includes pain induced by nonpainful stimulation (allodynia) and increased sensitivity to painful stimulation (hyperalgesia). ${ }^{16}$ Spontaneous pain is continuous or paroxysmal, and occurs independent of stimulation. CPSP commonly presents in the distal parts of the body, such as the hand and foot, and is less commonly experienced in proximal regions such as the shoulder and thigh. ${ }^{14}$ Furthermore, the development of CPSP has been associated with sensory impairment. ${ }^{17-19}$ In previous studies, the prevalence of CPSP was found to be $8 \%$ in patients with stroke. ${ }^{20,21}$ CPSP can occur following a lesion involving the thalamus (ventral posterolateral and ventral posteromedial nuclei) and/or the

(c) 2021. Thieme. All rights reserved. Thieme Medical Publishers, Inc., 333 Seventh Avenue, 18th Floor, New York, NY 10001, USA
DOI https://doi.org/ 10.1055/s-0040-1722641. ISSN 0271-8235. 
Table 1 The pathophysiology and treatment of poststroke pain

\begin{tabular}{|l|l|l|}
\hline & Pathophysiology & Treatment \\
\hline $\begin{array}{l}\text { Central poststroke } \\
\text { pain }\end{array}$ & $\begin{array}{l}\text { Neuronal excitability } \rightarrow \text { central sensitization, } \\
\text { hyperexcitability of the spinothalamic tract }\end{array}$ & Oral medication, deep brain stimulation, rTMS \\
\hline $\begin{array}{l}\text { Complex regional } \\
\text { pain syndrome }\end{array}$ & $\begin{array}{l}\text { Hyperactivity of sympathetic nervous system, } \\
\text { persistent noxious input } \rightarrow \text { central sensitization, } \\
\text { overactivation of inflammatory response }\end{array}$ & $\begin{array}{l}\text { Oral medication (including oral prednisolone), } \\
\text { sympathetic blockade, spinal cord stimulation, } \\
\text { active or passive mobilization, massage, contrast } \\
\text { baths, TENS }\end{array}$ \\
\hline Shoulder pain & Immobilization, weakness, spasticity & $\begin{array}{l}\text { Oral medication, corticosteroid injection, passive } \\
\text { ROM exercise, NMES, rTMS }\end{array}$ \\
\hline $\begin{array}{l}\text { Spasticity-related } \\
\text { pain }\end{array}$ & $\begin{array}{l}\text { Abnormal distribution of mechanical loading } \rightarrow \\
\text { additional mechanical stress }\end{array}$ & $\begin{array}{l}\text { Oral antispasticity medication, neurolysis with } \\
\text { alcohol or phenol, botulinum toxin injection, } \\
\text { stretching exercise, NMES, rTMS, serial casting, } \\
\text { brace, surgery }\end{array}$ \\
\hline Headache & $\begin{array}{l}\text { Altered biomechanics, poor posture, stimulation of } \\
\text { trigeminovascular afferents, dural stretch by mass } \\
\text { effect }\end{array}$ & $\begin{array}{l}\text { Oral medication, botulinum toxin injection, oc- } \\
\text { cipital nerve block, TPI, PRF stimulation, cognitive } \\
\text { behavioral therapy, biofeedback, exercise }\end{array}$ \\
\hline
\end{tabular}

Abbreviations: NMES, neuromuscular electrical stimulation; PRF, pulsed radiofrequency; ROM, range of motion; rTMS, repetitive transcranial magnetic stimulation; TENS, transcutaneous electrical nerve stimulation; TPI, trigger point injection.

spinothalamic tract (STT), which are structures responsible for the transmission of pain in the central nervous system (CNS). ${ }^{22,23}$ In particular, partial damage of the STT reportedly leads to a higher risk for the development of CPSP. ${ }^{22}$ In 2012, using diffusion tensor tractography, Hong et al demonstrated that the prevalence of CPSP in patients with partial injury of the STT was higher than that of patients with complete injury of the STT. ${ }^{22}$

\section{Pathophysiology of Central Poststroke Pain}

While the pathophysiology of the occurrence of CPSP has not yet been clearly elucidated, some possible mechanisms have been suggested. First, CNS lesions often induce neurochemical, excitotoxic, and inflammatory changes, which can increase neuronal excitability. ${ }^{24}$ This excitability may cause central sensitization, which in turn leads to chronic pain. Second, hyperexcitability and ongoing activity in the STT after STT injury could be responsible for CPSP. ${ }^{25}$ Third, central pain could be caused by a lesion in the lateral thalamus that interrupts inhibitory pathways, which results in disinhibition of the medial thalamus. ${ }^{26}$ Finally, thalamic changes after CNS lesions, including deafferentation, loss of inhibitory gamma amino butyric acid (GABA)-containing neurons in the thalamus, and microglial activation, are also proposed to underlie CPSP. ${ }^{27-30}$

\section{Treatment for Central Poststroke Pain}

The management of CPSP is often refractory and dosages may be limited due to side-effects. Various oral medications and nonpharmacological treatments are used to manage CPSP. Oral medications, including tricyclic antidepressants, selective serotonin reuptake inhibitors, and antiepileptics (such as gabapentin, pregabalin, and lamotrigine), have been reported to effectively control CPSP. ${ }^{31-33}$ Although opioids are not considered first-line agents, they have a role in effectively controlling CPSP. ${ }^{34}$ Intravenous lidocaine and propofol have been shown to alleviate CPSP during infusion, but studies on intravenous agents are limited to case reports. ${ }^{35,36}$ Nonphar- macological treatment options for CPSP include deep brain stimulation (DBS) and repetitive transcranial magnetic stimulation (rTMS). The success rate of DBS for managing CPSP has been reported to be around 50\% in previous studies. ${ }^{37,38}$ rTMS is a safe, noninvasive, and effective therapeutic intervention that uses an electromagnetic coil applied to the scalp to produce a magnetic field. ${ }^{39,40}$ This induces changes in cortical excitability at the stimulation site and transsynaptically at distant areas. ${ }^{39,40}$ The application of high-frequency unilateral rTMS to the motor cortex in patients with chronic pain may have long-term analgesic effects. Indeed, in 2015, Kobayashi et al applied high-frequency $(5 \mathrm{~Hz})$ rTMS to 18 patients with CPSP once a week for 12 weeks. Approximately $60 \%$ of the patients experienced pain reduction at 12 weeks after initiating rTMS ${ }^{41}$ However, the study involved a limited number of individuals and lacked a control group, making it difficult to draw any definite conclusions regarding the long-term pain reduction effects of rTMS.

\section{Complex Regional Pain Syndrome}

CRPS is a chronic severe pain condition usually affecting the limbs (hand, arm, foot, or leg), and is accompanied by increased sensitivity to tactile stimulation, vasomotor changes including edema and changes in skin temperature and color, limited range of motion, and osteopenia. ${ }^{42}$ Its cause is not clearly understood, but it is believed to be a result of damage to both the peripheral and CNS. ${ }^{42}$ CRPS is classified into two types: Type I, where there is no evidence of nerve damage in the affected limb, and Type II, where a distinct nerve lesion is present. CRPS following stroke is categorized as Type I CRPS. ${ }^{43}$ Because there is little consensus on diagnostic criteria for CRPS, the reported incidence of CRPS after stroke is highly variable and ranges from 2 to $49 \%{ }^{44,45}$ Recently, the Budapest criteria were developed to aid in the standardization of the diagnosis of CRPS (- Table 2). ${ }^{46}$ Three-phase bone scan and digital infrared thermal imaging can be used as supportive 
Table 2 The Budapest clinical diagnostic criteria for complex regional pain syndrome

\begin{tabular}{|l}
\hline $\begin{array}{l}\text { 1. Continuing pain, which is disproportionate to any incitin } \\
\text { event }\end{array}$ \\
\hline $\begin{array}{l}\text { 2. Must report at least one symptom in all four of the } \\
\text { following categories: }\end{array}$ \\
\hline Sensory: reports of hyperaesthesia and/or allodynia \\
\hline $\begin{array}{l}\text { Vasomotor: reports of temperature asymmetry and/or } \\
\text { skin color changes and/or skin color asymmetry }\end{array}$
\end{tabular}

Sudomotor/edema: reports of edema and/or sweating changes and/or sweating asymmetry

Motor/trophic: reports of decreased range of motion and/ or motor dysfunction (weakness, tremor, dystonia) and/or trophic changes (hair, nail, skin)

3. Must display at least one sign at time of evaluation in two or more of the following categories:

Sensory: evidence of hyperalgesia (to pinprick) and/or allodynia (to light touch and/or temperature sensation and/or deep somatic pressure and/or joint movement)

Vasomotor: evidence of temperature asymmetry $\left(>1^{\circ} \mathrm{C}\right)$ and/or skin color changes and/or asymmetry

Sudomotor/edema: evidence of edema and/or sweating changes and/or sweating asymmetry

Motor/trophic: evidence of decreased range of motion and/or motor dysfunction (weakness, tremor, dystonia) and/or trophic changes (hair, nail, skin)

4. There is no other diagnosis that better explains the signs and symptoms

diagnostic tools for CRPS. ${ }^{47,48}$ Wüppenhorst et al reported that the sensitivity and specificity of three-phase bone scan for diagnosing CRPS were 31 to $50 \%$ and 83 to $100 \%$, respectively. ${ }^{49}$ Thus far, no studies on the sensitivity and specificity in digital infrared thermal imaging have been conducted.

Pathophysiology of Complex Regional Pain Syndrome Several mechanisms have been suggested to contribute to CRPS, some of which may coexist. Local hyperactivity of the sympathetic nervous system has been proposed to be one of the causes of CRPS. ${ }^{50}$ This has been supported by several previous studies reporting that local anesthetic blockade of the sympathetic chain effectively controlled CRPS symptoms. ${ }^{51-53}$ Furthermore, persistent noxious input resulting from nerve damage increases the excitability of nociceptive neurons in the spinal cord, referred to as central sensitization. ${ }^{54}$ Central sensitization results in hyperesthesia, allodynia, and hyperalgesia. Overactivation of inflammatory responses or relative hypoxia of the affected limb may also contribute to the development of CRPS. ${ }^{55-57}$

\section{Treatment of Complex Regional Pain Syndrome}

While there is no gold standard for the treatment of CRPS, outcomes are better when CRPS is treated earlier. ${ }^{58}$ Several oral medications, such as steroids, antiepileptics, opioids, nonsteroidal anti-inflammatory drugs and antidepressants, are currently used to reduce pain and to improve the functional status of patients with CRPS, although there is a lack of convincing evidence for the efficacy of these medications. ${ }^{59}$ The commonly used medications for alleviating pain from CRPS are anti-inflammatory agents, analgesics, antidepressants, oral muscle relaxants, anticonvulsants, and topical agents. ${ }^{60-62}$ On the basis of theoretical evidence that inflammation is responsible for the pathogenesis and propagation of CRPS, oral prednisolone therapy has also been studied. ${ }^{61,63}$ Atalay et $\mathrm{al}^{63}$ investigated the effect of oral prednisolone for CPRS of the upper extremity. They retrospectively reviewed the medical records of 45 patients with CRPS who were treated with $30 \mathrm{mg}$ prednisolone and tapered the dose by $5 \mathrm{mg}$ every 3 days until discontinuation after 3 weeks. After the treatment, patients' CRPS symptoms, such as pain, sweating, stiffness, cold intolerance, and cyanosis, were significantly reduced. Additionally, several previous studies have found that repeated sympathetic blockade with local anesthetics can attenuate CRPS symptoms. ${ }^{51-53}$ In refractory cases of CRPS, spinal cord stimulation was found to have potential to relieve such symptoms. ${ }^{64}$ In addition to the aforementioned medications and procedures, combined treatment with active or passive mobilization, massage, contrast baths, and transcutaneous electrical nerve stimulation have been used as adjunctive therapies to help manage CRPS, although data regarding efficacy are limited. ${ }^{65}$

\section{Shoulder Pain}

Shoulder pain is one of the most common nociceptive pain syndromes after stroke, occurring in approximately $75 \%$ of patients with stroke. ${ }^{66}$ Pain usually begins within 3 weeks of the stroke. ${ }^{67}$ In particular, shoulder pain frequently occurs in those with severe motor deficits or spasticity in the affected upper extremity. ${ }^{68,69}$ Although the majority of cases of shoulder pain after stroke resolve by 6 months, approximately $20 \%$ of patients complain of persistent and debilitating shoulder pain. ${ }^{70}$ Shoulder pain is known to lead to poor functional recovery. In 2012, Pong et $\mathrm{al}^{71}$ conducted a prospective study to evaluate the correlation between shoulder pain and stroke recovery in 67 acute stroke patients with hemiplegic shoulder. At follow-up evaluation in the chronic stage, shoulder pain was significantly correlated with worse recovery of shoulder function.

\section{Pathophysiology of Shoulder Pain}

The development of shoulder pain is known to be multifactorial, and several factors such as glenohumeral subluxation, impingement, rotator cuff tears, glenohumeral capsulitis, and weakness and spasticity are thought to be involved..$^{5,70}$ The shoulder joint is loosely constrained by a thin joint capsule attached along the outside ring of the glenoid cavity and the anatomical neck of the humerus. ${ }^{72}$ Stability of the shoulder joint depends on the surrounding muscles and ligaments. Therefore, weakness in these surrounding muscles following stroke can cause instability or immobilization of the glenohumeral joint. ${ }^{73}$ This instability can lead to impingement and rotator cuff tears. Also, immobilization after stroke is a risk factor of glenohumeral capsulitis. Flaccid 
upper-extremity muscle tone can also cause glenohumeral subluxation, and the spasticity alters the equilibrium between the shoulder abductor/adductor and internal/ external rotator muscles. ${ }^{7,74}$ Glenohumeral subluxation and imbalance between the shoulder muscles lead to shoulder instability and limitation of shoulder joint motion, which can also lead to shoulder pain.,74

\section{Treatment of Shoulder Pain}

The management of poststroke shoulder pain should begin first with its prevention. Patients who have severe weakness in their upper extremity prior to the development of spasticity tend to develop shoulder laxity. ${ }^{75}$ Early stabilization of the patient's shoulder joint using passive range of motion exercises on the affected side may help prevent shoulder pain. ${ }^{75}$ Slings are also used in patients with glenohumeral subluxation and severe motor weakness of shoulder elevators to both prevent and manage shoulder pain after stroke. ${ }^{76}$ However, immobilization is a major risk factor for adhesive capsulitis or shoulder joint contracture, so long-term use of slings is not recommended. ${ }^{77}$ External support using a sling can be discontinued when the muscle tone around the glenohumeral joint is sufficient to prevent subluxation. ${ }^{78}$ Functional electrical stimulation that targets the supraspinatus and posterior deltoid muscles has been found to prevent glenohumeral subluxation by maintaining isometric strength of the shoulder girdle. ${ }^{79}$ Linn et al recruited 40 patients with significant motor deficit of the upper limb after stroke, and randomly allocated 20 patients to the treatment group and 20 to the control group. ${ }^{79}$ The patients in the treatment group received functional electrical stimulation four times a day over 4 weeks (30-60 minutes/stimulation). The supraspinatus and posterior deltoid muscles were stimulated by two electrodes. The treatment group showed lesser subluxation on the radiographs and reduced pain during the treatment period. Range-of-motion exercises should also be used in patients who wear shoulder slings. ${ }^{75}$ Additionally, in patients using a wheelchair, the wheelchair lap tray can help maintain proper positioning of the shoulder and prevent glenohumeral subluxation. ${ }^{7}$

Several pharmacological and nonpharmacological interventions can be applied to manage poststroke shoulder pain. ${ }^{80}$ Nonsteroidal anti-inflammatory drugs, other oral analgesics, ${ }^{7,74,80}$ and antispasmodic medications have been shown to reduce spasticity. ${ }^{7,74,80}$ For the management of persistent pain that is unresponsive to oral medications, intra-articular or subacromial bursa corticosteroid injections may also be effective, likely related to anti-inflammatory mechanisms. ${ }^{5}$ In 2017 , Chang recruited 30 patients with poststroke shoulder pain and administered intra-articular or subacromial bursa corticosteroid injections into the shoulder joint under the guidance of ultrasonography. ${ }^{5}$ After the injections, the patients' shoulder pain was significantly relieved, passive range of shoulder motion was significantly increased, and the effects were sustained for at least 2 months. Treated patients also reported decreased rates of depression and anxiety. Although sample size was small, this study suggested that corticosteroid injections can be a beneficial treatment option for shoulder pain after stroke. Additionally, several previous studies have reported that injection of botulinum toxin into surrounding muscles, such as the pectoralis major and subscapularis, can alleviate poststroke shoulder pain, likely related to both antispasmodic and antinociceptive effects. ${ }^{81-83}$

Nonpharmacological treatments including passive rangeof-motion exercises can be performed easily and help control shoulder muscle tone. ${ }^{75}$ Transcutaneous neuromuscular electrical stimulation has also been proposed to control shoulder pain according to the gate-control theory of pain; this works by activating myelinated sensory fibers and disrupting the pain signals of unmyelinated C-fibers. ${ }^{84}$ rTMS might also be a possible adjuvant treatment option for shoulder pain. ${ }^{70}$ In 2018, Choi and Chang performed highfrequency $(10 \mathrm{~Hz})$ rTMS over the primary motor cortex of the affected hemisphere in 12 patients with chronic shoulder pain after stroke. ${ }^{70}$ They reported that 20 to $30 \%$ of initial shoulder pain was reduced after 10 sessions of rTMS. Surgical procedures, such as release of shoulder capsule or ligament and repair of rotator cuff tears, can be considered when conservative treatments have failed and motion limitation of the shoulder joint is severe to the point of functional impairment. ${ }^{85}$

\section{Spasticity-Related Pain}

About $65 \%$ of all patients with stroke develop spasticity. ${ }^{86}$ Spasticity is characterized by a velocity-dependent increase in muscle tone during passive stretching, which results from hyperexcitability of the stretch reflex following upper motor neuron injury. ${ }^{86}$ Spasticity not only impairs functional outcome of patients with stroke, but is also associated with spasticity-related pain. ${ }^{87}$ In 2010 , Wissel et al reported a strong association between spasticity after stroke and pain. ${ }^{88}$ In that study, while $72 \%$ of patients with spasticity experienced pain, only $1.5 \%$ of nonspastic patients experienced pain. Therefore, appropriate management of spasticity is important for PSP management.

\section{Pathophysiology of Spasticity-Related Pain}

Spasticity-related pain is usually nociceptive, related to excess loading on muscles and ligaments resulting from spasticity. ${ }^{6}$ Persistent spasticity leads to changes in the rheologic properties of the involved muscles, which can lead to fibrosis and atrophy. ${ }^{89}$ In addition, in the lower leg, spasticity usually occurs in the ankle plantar flexor and inverter; accordingly, the mechanical loading on the foot during standing or walking is abnormally distributed. ${ }^{90,91}$ Loading imbalance can cause additional mechanical stress to the foot, which may cause pain in the joints or soft tissues. ${ }^{90,91}$

\section{Treatment of Spasticity-Related Pain}

Oral antispasticity medications are first line in managing spasticity-related pain after stroke. ${ }^{92}$ These medications are broadly classified as GABA agonists that affect ion flux and include baclofen, dantrolene sodium, and benzodiazepines, as well as agents affecting $\alpha 2$ adrenal receptors, such as tizanidine and clonidine. ${ }^{92}$ When treating spasticity with 
oral medications, clinicians should be aware of the potential development of side effects, including fatigue, dry mouth, seizure, and liver dysfunction. Peripheral nerve blocks with ethyl alcohol or phenol and intramuscular botulinum toxin injections have been demonstrated to help manage spasticity in stroke. ${ }^{90,91,93}$ Case reports of neurolysis of the medial and lateral motor branches of the tibial nerve to the gastrocnemius muscle with $20 \%$ ethyl alcohol in stroke patients with refractory metatarsalgia and pain have been reported to improve spasticity in the ankle and foot, as well as reduce the abnormal distribution of loading on the foot. ${ }^{90,91}$ Stretching exercises, neuromuscular electrical stimulation, rTMS, serial casting, antispastic brace use, and surgery have also been used to control spasticity after stroke, although data regarding efficacy of these therapies remain limited. ${ }^{86}$

\section{Persistent Poststroke Headache}

Headache is common around the time of stroke onset. The reported frequency of headache at the acute stage of stroke ranges from 30 to $50 \%{ }^{94-97}$ However, persistent headache for months or years after stroke is underrecognized in clinical practice, despite being relatively common. ${ }^{98}$ Its prevalence has been reported to be approximately $10 \%$ of total stroke patients. ${ }^{99,100}$ The severity of persistent poststroke headache is described as moderate to severe, and may be worse than the headaches experienced in the acute phase. ${ }^{98}$ The most common types of persistent poststroke headache are probable tension type (50\%), followed by probable migraine type (31\%). ${ }^{98}$ Persistent headache after stroke has been associated with depression and anxiety in patients with stroke. ${ }^{99}$

\section{Pathophysiology of Persistent Poststroke Headache}

Several mechanisms have been suggested to underlie persistent poststroke headache. ${ }^{101-104}$ Altered biomechanics of the musculoskeletal system and poor posture following stroke stimulate pericranial myofascial structures, which can trigger sensitization of spinal and supraspinal central neurons resulting in chronic tension-type headaches. ${ }^{103,104}$ Alternatively, mechanical or chemical stimulation of the trigeminovascular afferents, which innervate extra- and intracranial vessels, may contribute to headache. ${ }^{101,102}$ Another possible underlying mechanism of persistent poststroke headache is dural stretch due to mass effect from infarction or hemorrhage, and ischemia to brainstem nuclei or the pain-sensitive dura. ${ }^{101,102}$

\section{Treatment of Persistent Poststroke Headache}

The treatment of persistent poststroke headache is challenging. Treatment strategies are chosen according to presumed headache type, and are similar to those in patients with headache unrelated to stroke. ${ }^{105}$ The oral medications used to treat migraine-type persistent poststroke headache include nonsteroidal anti-inflammatory drugs and antiemetic agents. ${ }^{106}$ Ergot derivatives and 5-hydroxytryptamine receptor agonists are usually avoided due to their vasoconstrictive effects. For tension-type headaches, ibuprofen, nonsteroidal anti-inflammatory drugs, and other oral analgesics can be used. ${ }^{106}$ Botulinum toxin injection, occipital nerve block, and trigger point injections are also available for these two types of headache. ${ }^{106,107}$ Recently, Kwak and Chang reported that pulsed radiofrequency stimulation to the greater occipital nerve can effectively manage refractory chronic migraine pain, although these were not specifically stroke-related headaches. ${ }^{107}$ Cognitive behavioral therapy, biofeedback, and exercise are also known to be beneficial nonpharmacological options for managing persistent poststroke headache. ${ }^{105,107}$ In 2015, Harris et al conducted a systematic review of cognitive behavioral therapy for the treatment of chronic headache in adults, and reviewed 10 randomized controlled trials. ${ }^{108}$ They concluded that cognitive behavioral therapy can be an effective treatment option for reducing the intensity, frequency, and duration of headache. Furthermore, in 2007, Ciancarelli et al reported that biofeedback reduced oxidative stress and migraine symptoms in 20 patients with chronic migraine. ${ }^{109}$ The researchers suggested that the decrement of oxidative stress results in muscular relaxation, which would be associated with controlled migraine symptoms. Exercise has also been proposed to increase $\beta$-endorphin and endocannabinoid in plasma, which can modulate patients' pain perception. ${ }^{110}$

\section{Conclusion}

Various pathophysiologies have been proposed to contribute to the development of PSP subtypes, and treatment modalities often target these proposed mechanisms. Nonetheless, PSP is often refractory to initial therapies, and randomized, controlled data regarding efficacy of treatment options is needed. Regardless of specific intervention, careful evaluation and early, aggressive treatment of PSP can enhance both functional recovery and quality of life in patients who are recovering from stroke.

\section{Disclosure}

The authors have no conflicts of interest to report.

\section{Funding}

The present study was supported by a National Research Foundation of Korea grand funded by the Korean government (grant no. NRF-2019M3E5D1A02068106).

\section{Acknowledgments}

None.

\section{References}

1 Choi-Kwon S, Choi SH, Suh M, et al. Musculoskeletal and central pain at 1 year post-stroke: associated factors and impact on quality of life. Acta Neurol Scand 2017;135(04):419-425

2 Paolucci S, Iosa M, Toni D, et al;Neuropathic Pain Special Interest Group of the Italian Neurological Society. Prevalence and time course of post-stroke pain: a multicenter prospective hospitalbased study. Pain Med 2016;17(05):924-930

3 Naess $\mathrm{H}$, Lunde L, Brogger J. The effects of fatigue, pain, and depression on quality of life in ischemic stroke patients: the Bergen Stroke Study. Vasc Health Risk Manag 2012;8:407-413

4 O’Donnell MJ, Diener HC, Sacco RL, Panju AA, Vinisko R, Yusuf SPRoFESS Investigators. Chronic pain syndromes after ischemic stroke: PRoFESS trial. Stroke 2013;44(05):1238-1243 
5 Chang MC. The effects of ultrasound-guided corticosteroid injection for the treatment of hemiplegic shoulder pain on depression and anxiety in patients with chronic stroke. Int J Neurosci 2017; 127(11):958-964

6 Lundström E, Smits A, Terént A, Borg J. Risk factors for strokerelated pain 1 year after first-ever stroke. Eur J Neurol 2009;16 (02):188-193

7 Treister AK, Hatch MN, Cramer SC, Chang EY. Demystifying poststroke pain: from etiology to treatment. PM R 2017;9(01): 63-75

8 Delpont B, Blanc C, Osseby GV, Hervieu-Bègue M, Giroud M, Béjot Y. Pain after stroke: a review. Rev Neurol (Paris) 2018;174(10): 671-674

9 Henry JL, Lalloo C, Yashpal K. Central poststroke pain: an abstruse outcome. Pain Res Manag 2008;13(01):41-49

10 Klit H, Finnerup NB, Jensen TS. Central post-stroke pain: clinical characteristics, pathophysiology, and management. Lancet Neurol 2009;8(09):857-868

11 Hansen AP, Marcussen NS, Klit H, Andersen G, Finnerup NB, Jensen TS. Pain following stroke: a prospective study. Eur J Pain 2012;16(08):1128-1136

12 Klit H, Finnerup NB, Andersen G, Jensen TS. Central poststroke pain: a population-based study. Pain 2011;152(04):818-824

13 de Oliveira RA, de Andrade DC, Machado AG, Teixeira MJ. Central poststroke pain: somatosensory abnormalities and the presence of associated myofascial pain syndrome. BMC Neurol 2012;12:89

14 Kumar B, Kalita J, Kumar G, Misra UK. Central poststroke pain: a review of pathophysiology and treatment. Anesth Analg 2009; 108(05):1645-1657

15 Lin $\mathrm{CH}$, Chen $\mathrm{KH}$, Chang $\mathrm{CH}$, et al. Muscle pain intensity and pressure pain threshold changes in different periods of stroke patients. Am J Phys Med Rehabil 2014;93(04):299-309

16 Greenspan JD, Ohara S, Sarlani E, Lenz FA. Allodynia in patients with post-stroke central pain (CPSP) studied by statistical quantitative sensory testing within individuals. Pain 2004;109(03): 357-366

17 Castel A, Hélie P, Beaudry F, Vachon P. Bilateral central pain sensitization in rats following a unilateral thalamic lesion may be treated with high doses of ketamine. BMC Vet Res 2013;9:59

18 Kalita J, Kumar B, Misra UK, Pradhan PK. Central post stroke pain: clinical, MRI, and SPECT correlation. Pain Med 2011;12(02): 282-288

19 Landerholm ÅH, Hansson PT. Mechanisms of dynamic mechanical allodynia and dysesthesia in patients with peripheral and central neuropathic pain. Eur J Pain 2011;15(05):498-503

20 Andersen G, Vestergaard K, Ingeman-Nielsen M, Jensen TS. Incidence of central post-stroke pain. Pain 1995;61(02):187-193

21 Kong KH, Woon VC, Yang SY. Prevalence of chronic pain and its impact on health-related quality of life in stroke survivors. Arch Phys Med Rehabil 2004;85(01):35-40

22 Hong JH, Choi BY, Chang $\mathrm{CH}$, et al. The prevalence of central poststroke pain according to the integrity of the spino-thalamocortical pathway. Eur Neurol 2012;67(01):12-17

23 Kim JS. Pure sensory stroke. Clinical-radiological correlates of 21 cases. Stroke 1992;23(07):983-987

24 Vestergaard K, Nielsen J, Andersen G, Ingeman-Nielsen M, Arendt-Nielsen L, Jensen TS. Sensory abnormalities in consecutive, unselected patients with central post-stroke pain. Pain 1995;61(02):177-186

25 Wasner G, Lee BB, Engel S, McLachlan E. Residual spinothalamic tract pathways predict development of central pain after spinal cord injury. Brain 2008;131(Pt 9):2387-2400

26 Head H, Holmes G. Sensory disturbances from cerebral lesions. Brain 1911;34:102-254

27 Neto FL, Ferreira-Gomes J, Castro-Lopes JM. Distribution of GABA receptors in the thalamus and their involvement in nociception. Adv Pharmacol 2006;54:29-51
28 Pattany PM, Yezierski RP, Widerström-Noga EG, et al. Proton magnetic resonance spectroscopy of the thalamus in patients with chronic neuropathic pain after spinal cord injury. AJNR Am J Neuroradiol 2002;23(06):901-905

29 Ralston HJ III. Pain and the primate thalamus. Prog Brain Res 2005;149:1-10

30 Zhao P, Waxman SG, Hains BC. Modulation of thalamic nociceptive processing after spinal cord injury through remote activation of thalamic microglia by cysteine-cysteine chemokine ligand 21. J Neurosci 2007;27(33):8893-8902

31 Jungehulsing GJ, Israel $\mathrm{H}$, Safar N, et al. Levetiracetam in patients with central neuropathic post-stroke pain-a randomized, double-blind, placebo-controlled trial. Eur J Neurol 2013;20(02): 331-337

32 Pellicane AJ, Millis SR. Efficacy of methylprednisolone versus other pharmacologic interventions for the treatment of central post-stroke pain: a retrospective analysis. J Pain Res 2013; 6:557-563

33 Widar M, Samuelsson L, Karlsson-Tivenius S, Ahlström G. Longterm pain conditions after a stroke. J Rehabil Med 2002;34(04): $165-170$

34 Dworkin RH, O'Connor AB, Backonja M, et al. Pharmacologic management of neuropathic pain: evidence-based recommendations. Pain 2007;132(03):237-251

35 Attal N, Gaudé V, Brasseur L, et al. Intravenous lidocaine in central pain: a double-blind, placebo-controlled, psychophysical study. Neurology 2000;54(03):564-574

36 Canavero S, Bonicalzi V. Intravenous subhypnotic propofol in central pain: a double-blind, placebo-controlled, crossover study. Clin Neuropharmacol 2004;27(04):182-186

37 Saitoh Y, Yoshimine T. Stimulation of primary motor cortex for intractable deafferentation pain. Acta Neurochir Suppl (Wien) 2007;97(Pt 2):51-56

38 Sokal P, Harat M, Zieliński P, Furtak J, Paczkowski D, Rusinek M. Motor cortex stimulation in patients with chronic central pain. Adv Clin Exp Med 2015;24(02):289-296

39 Choi GS, Kwak SG, Lee HD, Chang MC. Effect of high-frequency repetitive transcranial magnetic stimulation on chronic central pain after mild traumatic brain injury: a pilot study. J Rehabil Med 2018;50(03):246-252

$40 \mathrm{Gu}$ SY, Chang MC. The effects of $10-\mathrm{Hz}$ repetitive transcranial magnetic stimulation on depression in chronic stroke patients. Brain Stimul 2017;10(02):270-274

41 Kobayashi M, Fujimaki T, Mihara B, Ohira T. Repetitive transcranial magnetic stimulation once a week induces sustainable long-term relief of central poststroke pain. Neuromodulation 2015;18(04):249-254

$42 \mathrm{Oh} \mathrm{HM}$, Kim CH, Kim AR. Dramatic effect in passive ROM exercise under sedation in a patient with intractable complex regional pain syndrome (type I): a case report. Medicine (Baltimore) 2019;98(13):e14990

$43 \mathrm{Kim} \mathrm{H}$, Lee $\mathrm{CH}$, Kim SH, Kim YD. Epidemiology of complex regional pain syndrome in Korea: an electronic population health data study. PLoS One 2018;13(06):e0198147

44 Kocabas H, Levendoglu F, Ozerbil OM, Yuruten B. Complex regional pain syndrome in stroke patients. Int J Rehabil Res 2007;30(01):33-38

45 McLean DE. Medical complications experienced by a cohort of stroke survivors during inpatient, tertiary-level stroke rehabilitation. Arch Phys Med Rehabil 2004;85(03):466-469

46 Harden RN, Bruehl S, Stanton-Hicks M, Wilson PR. Proposed new diagnostic criteria for complex regional pain syndrome. Pain Med 2007;8(04):326-331

47 Kwon HW, Paeng JC, Nahm FS, et al. Diagnostic performance of three-phase bone scan for complex regional pain syndrome type 1 with optimally modified image criteria. Nucl Med Mol Imaging 2011;45(04):261-267 
$48 \mathrm{Nahm}$ FS. Infrared thermography in pain medicine. Korean J Pain 2013;26(03):219-222

49 Wüppenhorst N, Maier C, Frettlöh J, Pennekamp W, Nicolas V. Sensitivity and specificity of 3-phase bone scintigraphy in the diagnosis of complex regional pain syndrome of the upper extremity. Clin J Pain 2010;26(03):182-189

50 Coderre TJ, Bennett GJ. A hypothesis for the cause of complex regional pain syndrome-type I (reflex sympathetic dystrophy): pain due to deep-tissue microvascular pathology. Pain Med 2010;11(08):1224-1238

51 Datta R, Agrawal J, Sharma A, Rathore VS, Datta S. A study of the efficacy of stellate ganglion blocks in complex regional pain syndromes of the upper body. J Anaesthesiol Clin Pharmacol 2017;33(04):534-540

52 Dev S, Yoo Y, Lee HJ, Kim DH, Kim YC, Moon JY. Does temperature increase by sympathetic neurolysis improve pain in complex regional pain syndrome? A retrospective cohort study. World Neurosurg 2018;109:e783-e791

53 Kim ED, Yoo WJ, Kim YN, Park HJ. Ultrasound-guided pulsed radiofrequency treatment of the cervical sympathetic chain for complex regional pain syndrome: a retrospective observational study. Medicine (Baltimore) 2017;96(01):e5856

54 Sebastin SJ. Complex regional pain syndrome. Indian J Plast Surg 2011;44(02):298-307

55 Koban M, Leis S, Schultze-Mosgau S, Birklein F. Tissue hypoxia in complex regional pain syndrome. Pain 2003;104(1-2):149-157

56 Okudan B, Celik C. Determination of inflammation of reflex sympathetic dystrophy at early stages with Tc-99m HIG scintigraphy: preliminary results. Rheumatol Int 2006;26(05):404-408

57 Schinkel C, Gaertner A, Zaspel J, Zedler S, Faist E, Schuermann M. Inflammatory mediators are altered in the acute phase of posttraumatic complex regional pain syndrome. Clin J Pain 2006;22(03):235-239

58 Winston P. Early treatment of acute complex regional pain syndrome after fracture or injury with prednisone: Why is there a failure to treat? A case series. Pain Res Manag 2016;2016:7019196

59 Palmer G. Complex regional pain syndrome. Aust Prescr 2015;38 (03):82-86

60 Harke H, Gretenkort P, Ladleif HU, Rahman S, Harke O. The response of neuropathic pain and pain in complex regional pain syndrome I to carbamazepine and sustained-release morphine in patients pretreated with spinal cord stimulation: a double-blinded randomized study. Anesth Analg 2001;92(02): 488-495

61 Kingery WS. A critical review of controlled clinical trials for peripheral neuropathic pain and complex regional pain syndromes. Pain 1997;73(02):123-139

62 van de Vusse AC, Stomp-van den Berg SG, Kessels AH, Weber WE. Randomised controlled trial of gabapentin in complex regional pain syndrome type 1 [ISRCTN84121379]. BMC Neurol 2004; $4: 13$

63 Atalay NS, Ercidogan O, Akkaya N, Sahin F. Prednisolone in complex regional pain syndrome. Pain Physician 2014;17(02): 179-185

64 Visnjevac O, Costandi S, Patel BA, et al. A comprehensive outcomespecific review of the use of spinal cord stimulation for complex regional pain syndrome. Pain Pract 2017;17(04):533-545

65 Goh EL, Chidambaram S, Ma D. Complex regional pain syndrome: a recent update. Burns Trauma 2017;5:2

66 Ward AB. Hemiplegic shoulder pain. J Neurol Neurosurg Psychiatry 2007;78(08):789

67 Dromerick AW, Reding MJ. Functional outcome for patients with hemiparesis, hemihypesthesia, and hemianopsia. Does lesion location matter? Stroke 1995;26(11):2023-2026

68 Gamble GE, Barberan E, Laasch HU, Bowsher D, Tyrrell PJ, Jones AK. Poststroke shoulder pain: a prospective study of the association and risk factors in 152 patients from a consecutive cohort of 205 patients presenting with stroke. Eur J Pain 2002;6(06): 467-474

69 Rajaratnam BS, Venketasubramanian N, Kumar PV, Goh JC, Chan YH. Predictability of simple clinical tests to identify shoulder pain after stroke. Arch Phys Med Rehabil 2007;88(08): 1016-1021

70 Choi GS, Chang MC. Effects of high-frequency repetitive transcranial magnetic stimulation on reducing hemiplegic shoulder pain in patients with chronic stoke: a randomized controlled trial. Int J Neurosci 2018;128(02):110-116

71 Pong YP, Wang LY, Huang YC, Leong CP, Liaw MY, Chen HY. Sonography and physical findings in stroke patients with hemiplegic shoulders: a longitudinal study. J Rehabil Med 2012;44 (07):553-557

72 Precerutti M, Garioni E, Madonia L, Draghi F. US anatomy of the shoulder: pictorial essay. J Ultrasound 2010;13(04):179-187

73 Faghri PD, Rodgers MM, Glaser RM, Bors JG, Ho C, Akuthota P. The effects of functional electrical stimulation on shoulder subluxation, arm function recovery, and shoulder pain in hemiplegic stroke patients. Arch Phys Med Rehabil 1994;75(01):73-79

74 Harrison RA, Field TS. Post stroke pain: identification, assessment, and therapy. Cerebrovasc Dis 2015;39(3-4):190-201

75 Vasudevan JM, Browne BJ. Hemiplegic shoulder pain: an approach to diagnosis and management. Phys Med Rehabil Clin N Am 2014; 25(02):411-437

76 van Bladel A, Lambrecht G, Oostra KM, Vanderstraeten G, Cambier D. A randomized controlled trial on the immediate and long-term effects of arm slings on shoulder subluxation in stroke patients. Eur J Phys Rehabil Med 2017;53(03):400-409

77 Stolzenberg D, Siu G, Cruz E. Current and future interventions for glenohumeral subluxation in hemiplegia secondary to stroke. Top Stroke Rehabil 2012;19(05):444-456

78 McCollough NC III. The role of the orthopedic surgeon in the treatment of stroke. Orthop Clin North Am 1978;9(02):305-324

79 Linn SL, Granat MH, Lees KR. Prevention of shoulder subluxation after stroke with electrical stimulation. Stroke 1999;30(05): 963-968

80 Wilson RD, Chae J. Hemiplegic shoulder pain. Phys Med Rehabil Clin N Am 2015;26(04):641-655

81 Lim JY, Koh JH, Paik NJ. Intramuscular botulinum toxin-A reduces hemiplegic shoulder pain: a randomized, double-blind, comparative study versus intraarticular triamcinolone acetonide. Stroke 2008;39(01):126-131

82 Marciniak CM, Harvey RL, Gagnon CM, et al. Does botulinum toxin type A decrease pain and lessen disability in hemiplegic survivors of stroke with shoulder pain and spasticity?: a randomized, double-blind, placebo-controlled trial Am J Phys Med Rehabil 2012;91(12):1007-1019

83 Marco E, Duarte E, Vila J, et al. Is botulinum toxin type A effective in the treatment of spastic shoulder pain in patients after stroke? A double-blind randomized clinical trial. J Rehabil Med 2007;39 (06):440-447

84 Zhou M, Li F, Lu W, Wu J, Pei S. Efficiency of neuromuscular electrical stimulation and transcutaneous nerve stimulation on hemiplegic shoulder pain: a randomized controlled trial. Arch Phys Med Rehabil 2018;99(09):1730-1739

85 Walsh K. Management of shoulder pain in patients with stroke. Postgrad Med J 2001;77(912):645-649

$86 \mathrm{Kim}$ EH, Chang MC, Seo JP, Jang SH, Song JC, Jo HM. The effect of a hand-stretching device during the management of spasticity in chronic hemiparetic stroke patients. Ann Rehabil Med 2013;37 (02):235-240

87 Francisco GE, McGuire JR. Poststroke spasticity management. Stroke 2012;43(11):3132-3136

88 Wissel J, Schelosky LD, Scott J, Christe W, Faiss JH, Mueller J. Early development of spasticity following stroke: a prospective, observational trial. J Neurol 2010;257(07):1067-1072 
89 Mayer NH. Clinicophysiologic concepts of spasticity and motor dysfunction in adults with an upper motoneuron lesion. Muscle Nerve Suppl 1997;6:S1-S13

90 Chang MC. Reduced foot pain after spasticity control with alcohol block in a patient with chronic hemiparetic stroke: a case report. J Phys Ther Sci 2017;29(04):767-770

91 Chang MC. Metatarsalgia in a patient with chronic hemiparetic stroke managed with alcohol block of the tibial nerve: a case report. Neurol Asia 2017;22(03):267-270

92 Bakheit AM. The pharmacological management of post-stroke muscle spasticity. Drugs Aging 2012;29(12):941-947

93 Santamato A, Cinone N, Panza F, et al. Botulinum toxin type A for the treatment of lower limb spasticity after stroke. Drugs 2019; 79(02):143-160

94 Arboix A, Massons J, Oliveres M, Arribas MP, Titus F. Headache in acute cerebrovascular disease: a prospective clinical study in 240 patients. Cephalalgia 1994;14(01):37-40

95 Ferro JM, Melo TP, Oliveira V, et al. A multivariate study of headache associated with ischemic stroke. Headache 1995;35 (06):315-319

96 Koudstaal PJ, van Gijn J, Kappelle LJDutch TIA Study Group. Headache in transient or permanent cerebral ischemia. Stroke 1991;22(06):754-759

97 Vestergaard K, Andersen G, Nielsen MI, Jensen TS. Headache in stroke. Stroke 1993;24(11):1621-1624

98 Hansen AP, Marcussen NS, Klit H, Kasch H, Jensen TS, Finnerup NB. Development of persistent headache following stroke: a 3-year follow-up. Cephalalgia 2015;35(05):399-409

99 Ferro JM, Melo TP, Guerreiro M. Headaches in intracerebral hemorrhage survivors. Neurology 1998;50(01):203-207

100 Klit H, Finnerup NB, Overvad K, Andersen G, Jensen TS. Pain following stroke: a population-based follow-up study. PLoS One 2011;6(11):e27607
101 Evans RW, Mitsias PD. Headache at onset of acute cerebral ischemia. Headache 2009;49(06):902-908

102 Mitsias P, Ramadan NM. Headache in ischemic cerebrovascular disease. Part II: Mechanisms and predictive value. Cephalalgia 1992;12(06):341-344

$103 \mathrm{Kim} \mathrm{JH}$, Suh SI, Seol HY, et al. Regional grey matter changes in patients with migraine: a voxel-based morphometry study. Cephalalgia 2008;28(06):598-604

104 Schmidt-Wilcke T, Leinisch E, Straube A, et al. Gray matter decrease in patients with chronic tension type headache. Neurology 2005;65(09):1483-1486

105 Lai J, Harrison RA, Plecash A, Field TS. A narrative review of persistent post-stroke headache - a new entry in the International Classification of Headache Disorders, 3rd edition. Headache 2018;58(09):1442-1453

106 Kahriman A, Zhu S. Migraine and tension-type headache. Semin Neurol 2018;38(06):608-618

107 Kwak S, Chang MC. Management of refractory chronic migraine using ultrasound-guided pulsed radiofrequency of greater occipital nerve: two case reports. Medicine (Baltimore) 2018;97 (45):e13127

108 Harris P, Loveman E, Clegg A, Easton S, Berry N. Systematic review of cognitive behavioural therapy for the management of headaches and migraines in adults. Br J Pain 2015;9(04): 213-224

109 Ciancarelli I, Tozzi-Ciancarelli MG, Spacca G, Di Massimo C, Carolei A. Relationship between biofeedback and oxidative stress in patients with chronic migraine. Cephalalgia 2007;27(10): 1136-1141

110 Amin FM, Aristeidou S, Baraldi C, et al;European Headache Federation School of Advanced Studies (EHF-SAS) The association between migraine and physical exercise. J Headache Pain 2018;19(01):83 